\title{
Simulation of Microstructure and Behavior of Interfacial Mold Slag Layers in Continuous Casting of Steel
}

\author{
Ya MENG and Brian G. THOMAS \\ University of Illinois at Urbana-Champaign, Department of Mechanical and Industrial Engineering, 1206 West Green Street, \\ Urbana, IL USA 61801. E-mail: bgthomas@uiuc.edu
}

(Received on August 30, 2005; accepted on February 24, 2006)

\begin{abstract}
A computational model of heat transfer, solidification and interface behavior during the continuous casting of steel is applied to interpret the crystallization behavior of slag layers in the interfacial gap between the mold and the steel shell. A mechanism for the formation of this crystalline layer is proposed that combines the effects of a shift in the viscosity curve, a decrease in the liquid slag conductivity due to partial crystallization, and an increase in the solid slag layer roughness corresponding to a decrease in solid layer surface temperature with distance down the mold. When the shear stress exceeds the slag shear strength before the axial stress accumulates to the fracture strength, the slag could shear longitudinally inside the layers. The predictions are consistent with measurements conducted in the real process and with the microstructure of analyzed slag samples.
\end{abstract}

KEY WORDS: crystallization; glass transition; interfacial gap; heat transfer; mold slag; numerical model; continuous casting.

\section{Introduction}

In continuous casting of steel, the interfacial gap between the mold and the solidifying shell controls heat transfer in the process and is responsible for lubrication and the prevention of cracks and other defects. Mold slag forms when mold powder added to the top surface of the steel melts, and is the best current practice to perform these important functions. The properties and behavior of the slag depend greatly on its microstructure, which ranges from crystalline to glassy. Thus, there is a great incentive to predict the slag microstructure, by quantitative understanding of the phenomena which occur in the interfacial gap.

Figure 1 shows the typical structure of interfacial slag layers in samples obtained from the mold walls during operation. The slag layer adjacent to the cold mold wall cools and greatly increases in viscosity, thus acting as a re-solidified solid layer. Its thickness increases greatly just above the meniscus, where it is called the "slag rim". Depending on its composition and cooling history, the microstructure of this layer could be glassy, crystalline or mixtures of both. ${ }^{1)}$ The slag is consumed into the gap, and carried downwards in a highly transient and non-uniform manner. The solid layer often remains stuck to the mold wall, but it sometimes may be dragged intermittently downward at an average speed far less than the casting speed. ${ }^{2-4)}$ However, the mechanism of slag layer flow, fracture, and attachment is not yet understood well.

The behavior of the interfacial slag layers is revealed experimentally only through indirect means, including analysis of slag samples, monitoring of mold heat transfer, and characterization of the mold slag properties. Heat transfer is inferred from the heat-up of the mold cooling water and thermocouples measurements of the mold wall temperature together reveal the heat flux profile down the mold. Breakout shell thickness measurements reveal the corre- sponding growth profile of the solidified steel shell. The rate of consumption of the mold slag into the gap can be measured, and shows a decrease with increasing casting speed. ${ }^{5)}$ Optimal design of the mold slag is needed to help avoid surface defects such as longitudinal, transverse and star cracks; enhance surface quality with the formation of uniform and shallow oscillation marks; prevent breakouts; and enable increased casting speed.

Many properties of the mold slag must be measured in order to understand and quantify these phenomena, and improve casting quality. Traditionally, the mold slag properties are characterized by the temperature-dependent viscosity of the liquid slag, which has been quantified reliably as a function of powder composition. ${ }^{6}$ However, the powder melting rate, solidification temperature and crystallinity of the slag are more important for predicting lubrication, heat transfer, ${ }^{7)}$ and steel quality. ${ }^{8)}$ The microstructure of the slag layer can be determined by measuring its Time-Temperature-

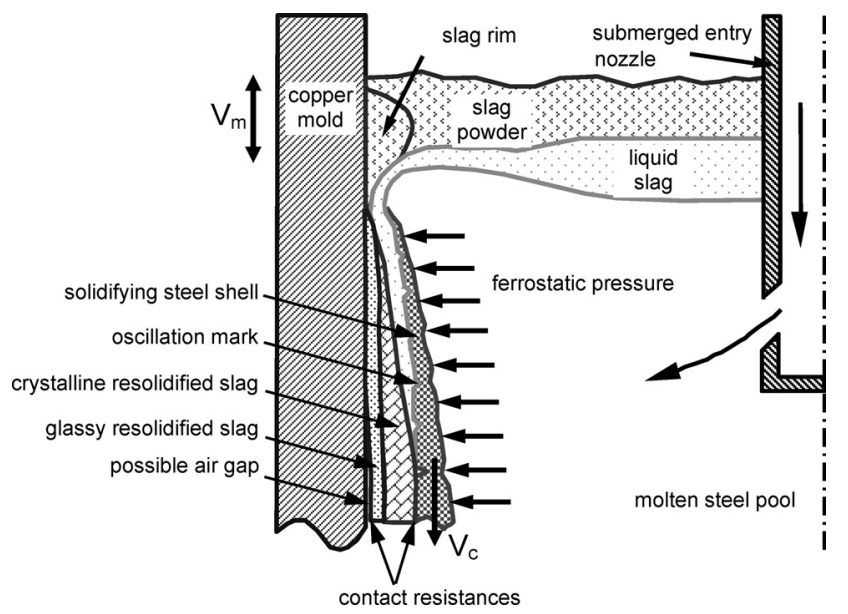

Fig. 1. Typical slag layer structure in continuous casting process. 
Transformation (TTT) diagram. ${ }^{7,9,10)}$ In recent work, other important mold powder properties were revealed, including the entire viscosity-temperature curve down to the glass transition temperature, ${ }^{7}$ the friction coefficient between the slag and the mold wall, ${ }^{7)}$ and the strength of the slag layer. ${ }^{11)}$ Measurements show that with decreasing temperature of the slag cold surface, the contact resistance between the mold and solid layers increases, due to an increase of the solid slag layer surface roughness. ${ }^{12)}$

Many mathematical models simulate the heat flux through the different slag layers including the effect of both conduction $^{13)}$ and thickness. ${ }^{14,15)}$ A few researchers have attempted to couple the heat transfer to slag hydrodynamics with simplified treatment of the gap, such as constant slag viscosity, ${ }^{16)}$ constant gap thickness, ${ }^{17)}$ a linearly increasing gap with distance ${ }^{18)}$ or using shell shrinkage as the interfacial gap. ${ }^{19)} \mathrm{A}$ more comprehensive review of these models is given elsewhere. ${ }^{3)}$

A comprehensive mathematical model of heat transfer, solidification and interfacial phenomena in continuous casting of steel, CON1D, is applied in this study. ${ }^{20,21)}$ The model connects slag crystallization together with gap heat transfer for the first time. It calculates the stress distribution within the slag layers, and transient friction along the mold, which enable the prediction of solid layer fracture and the sliding behavior of the slag layers. Moreover, the model has the flexibility to incorporate variable slag viscosity, solid slag layer velocity and gap contact resistance down the mold to account for the complex interfacial gap phenomena in the real caster.

Based on extensive plant measurements and metallographic analysis of samples, a case study analysis of a commercial caster under practical casting conditions is conducted in this work to predict heat transfer, interfacial phenomena and to interpret caster signals such as a "thermal hysteresis" thermocouple measurement and a sheared crystalline layer in the cap-off slag film sample. ${ }^{2)}$ Specifically, the CON1D model, ${ }^{21)}$ is used to predict temperature in the mold and shell, shell growth, interfacial slag layer thickness and microstructure, and friction phenomena. The predictions are compared wherever possible with measurements reported previously, ${ }^{22)}$ and with further metallurgical investigations included in this work.

\section{Phenomena}

Many complex inter-related phenomena occur in the interfacial gap between the mold and solidifying steel shell. They occur over three distinct time scales: oscillation cycle, mold residence time, and long-event time.

During each oscillation cycle, liquid mold slag is pumped from the top surface into the interfacial gap between the mold and steel shell at the meniscus. This creates cyclic variations in steel shell shape called "oscillation marks", with corresponding fluctuations in mold slag consumption, interfacial gap thickness, and local heat transfer rate. ${ }^{23)}$ All of these phenomena experience periodic variations at the frequency of the mold oscillation cycle of $60-180 \mathrm{~Hz}$. During part of the cycle, called the "negative strip time", the mold moves downward faster than the casting speed and pushes on the shell, causing compressive friction that is essential to stable casting. During the rest of the cycle, the mold tends to pull upward on the shell, causing tension or "positive strip". Each oscillation cycle creates a surface depression that decreases the local rate of heat transfer from the shell to the mold. Later, as the oscil- lation marks and other surface depressions in the shell move down the mold at the casting speed, they cause a local drop in the heat transfer rate. ${ }^{24)}$ Measurement systems such as thermocouples in the mold walls are usually unable to detect these rapid fluctuations, which span less than $1 \mathrm{sec}$. The CON1D model used in this work accurately simulates only some of the variations in each cycle, such as slag velocity and friction, focusing mainly on the time-averaged behavior of other high-frequency phenomena.

As the shell moves down the mold, its thickness grows and surface temperature drops. This decreases the rate of heat transfer, slag layer thicknesses, and related properties with distance down the mold, which corresponds to the mold residence time (mold length/casting speed) of 20$60 \mathrm{~s}$. During stable operation, this intermediate time scale is the most important and representative of steady continuous casting. Important interfacial phenomena at this time scale include the withdrawal of liquid mold slag attached to the steel shell, while the remaining layers crystallize according to their residence times, TTT properties, and changing heat transfer conditions. The CON1D model used in this work aims to accurately capture the time-average of the important phenomena of this intermediate time scale.

As time during casting evolves, the interfacial slag layers can gradually evolve. For example, the solid slag layer might thicken over several hours as liquid mold slag accumulates in the gap, leading to gradually increasing slag residence time in the mold, increased crystallization of the solid layer, and decreased heat flux. Sudden fracture of the embrittled solid slag layer can decrease the average slag layer thickness over just a few mold residence times, with an accompanying increase in heat flux, and the cycle can begin again. Such long-term transient phenomena at this time scale of 15-60 min have been documented in plant operation by O'Malley. ${ }^{2)}$ Jenkins and Thomas ${ }^{14)}$ observed similar decreased heat flux during startup, which persisted for up to $1 \mathrm{~h}$. Ozgu ${ }^{25)}$ and Geist ${ }^{26)}$ both reported "saw-tooth" shaped temperature fluctuations low in the mold, which suggests periodic solid slag layer fracture and sheeting from the mold wall. ${ }^{2)}$ Detailed modeling of these long-time-scale phenomena has not been attempted previously and is beyond the scope of this work. Instead, the results from the steady time-average CON1D model are interpreted in light of this knowledge.

\section{Model Description}

\subsection{Heat Transfer and Solidification Model: CON1D}

A comprehensive model of heat transfer, solidification and interfacial phenomena in steady-state continuous casting of steel, CON1D, is applied in this study. The model includes a one-dimensional (1-D) transient finite difference heat conduction calculation in the solidifying steel shell coupled together with a two-dimensional (2-D) analytical solution of steady state heat conduction in the water-cold copper mold. ${ }^{20)}$ It features a detailed treatment of interfacial gap between the shell and the mold, including mass and momentum balance on the slag layers and the effect of oscillation marks. Details of this model are presented elsewhere. ${ }^{3,27)}$

Temperature in the solidifying steel shell is governed by the 1-D transient heat conduction equation:

$$
\rho_{\text {steel }} C p_{\text {steel }}^{*} \frac{\partial T}{\partial t}=k_{\text {steel }} \frac{\partial^{2} T}{\partial x^{2}}+\frac{\partial k_{\text {steel }}}{\partial T}\left(\frac{\partial T}{\partial x}\right)^{2}
$$


Table 1. Mold powder composition.

\begin{tabular}{llllllllll}
\hline $\mathrm{SiO}_{2}$ & $\mathrm{CaO}$ & $\mathrm{Al}_{2} \mathrm{O}_{3}$ & $\mathrm{CaF}_{2}$ & $\mathrm{Na}_{2} \mathrm{O}$ & $\mathrm{MgO}$ & $\mathrm{Fe}_{2} \mathrm{O}_{3}$ & $\mathrm{MnO}$ & $\mathrm{K}_{2} \mathrm{O}$ & $\mathrm{C}-$ Total \\
31.68 & 21.52 & 4.85 & 28.12 & 9.57 & 0.84 & 0.20 & 0.01 & 0.85 & 2.36 \\
\hline
\end{tabular}

Heat transfer across the interfacial gap governs the heat flux leaving the steel, $q_{\text {int }}$, to enter the mold. To calculate this at every position down the mold, the model evaluates an effective heat transfer coefficient, $h_{\text {gap }}$, between the surface temperature of the steel shell, $T_{\mathrm{s}}$, and the hot face of the mold wall, $T_{\text {hotc }}$ :

$$
q_{\text {int }}=h_{\text {gap }}\left(T_{\mathrm{s}}-T_{\text {hotc }}\right)
$$

The heat transfer coefficient depends on the thermal resistances of four different layers of materials contained in the gap: oscillation marks, liquid slag, solid slag and the air gap/contact resistance. In the liquid slag layer, which usually also includes the oscillation marks, these resistances can be divided into two components: radiation and conduction.

$$
\begin{aligned}
h_{\text {gap }}= & 1 /\left(\left(r_{\text {contact }}+\frac{d_{\text {air }}}{k_{\text {air }}}+\frac{d_{\text {solid }}}{k_{\text {solid }}}\right)\right. \\
& \left.+1 /\left(1 /\left(\frac{d_{\text {liquid }}}{k_{\text {liquid }}}+\frac{d_{\text {eff }}}{k_{\text {eff }}}\right)+h_{\text {rad }}\right)\right)
\end{aligned}
$$

The effective oscillation mark depth, $d_{\text {eff }}$, is an equivalent thickness based on a heat balance calculation to roughly match the heat transferred from a 2-D section of shell with an oscillation mark. ${ }^{3,28)}$ The oscillation mark conductivity, $k_{\text {eff }}$, drops from that of liquid slag to that of air when the surface temperature drops below the slag final solidification temperature.

Slag can be carried downward by the solid layer, the liquid layer, and in the oscillations marks:

$$
\frac{Q_{\text {slag }} \times V_{\mathrm{c}}}{\rho_{\text {slag }}}=V_{\text {solid }} d_{\text {solid }}+\bar{V}_{\text {liquid }} d_{\text {liquid }}+V_{\mathrm{c}} d_{\text {osc }} \cdots \ldots .
$$

where, $d_{\text {osc }}$, is the volume-averaged oscillation mark depth. The solid layer is attached to the mold wall near the meniscus where the friction is low. Down the mold, the increased friction likely causes the solid layer either to begin to move down along the mold wall at constant speed or to shear longitudinally between the layers. Therefore, the model assumes that the solid layer velocity down the mold, usually increases from zero at the meniscus to a small ratio of the casting speed, according to the force balance acting on it.. Assuming laminar Couette flow of the liquid slag layer, the velocity distribution can be solved from the following Navier-Strokes equation:

$$
\frac{\partial}{\partial x}\left(\mu \frac{\partial V_{z}}{\partial x}\right)=\left(\rho_{\text {steel }}-\rho_{\text {slag }}\right) g \text {. }
$$

with the boundary conditions of $V=V_{\mathrm{c}}$ at the steel shell/ liquid slag layer interface and $V=V_{\text {mold }}$ at the liquid/solid slag layer interface. The liquid and solid slag layer thicknesses are obtained by solving a fourth order polynomial equation found by combining Eqs. (3) and (4).

\subsection{Mold Slag Properties}

The model results depend greatly on the slag properties, which in turn affect the microstructure and properties.

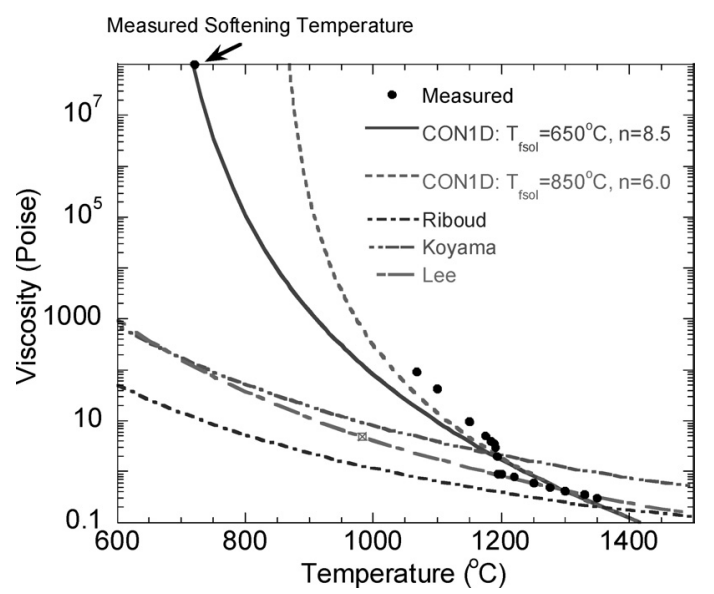

Fig. 2. Slag viscosity used in CON1D model compared with measurements $^{38)}$ and correlations by Riboud, ${ }^{29}$ Koyama $^{30)}$ and Lee. ${ }^{31)}$

\subsubsection{Viscosity}

The temperature dependent viscosity of the liquid slag is fit to a simple power-law relation, which better represents low-temperature high-viscosity behavior than a simple Arrhenius equation ${ }^{3)}$ :

$$
\mu=\mu_{\mathrm{o}}\left(\frac{T_{\mathrm{o}}-T_{\mathrm{fsol}}}{T-T_{\mathrm{fsol}}}\right)^{n}
$$

where the parameters $T_{\mathrm{fsol}}$ and $n$ are chosen empirically to fit measured viscosity data and $\mu_{\mathrm{o}}$ is the viscosity measured at the reference temperature, $T_{0}$, chosen to here be $1300^{\circ} \mathrm{C}$ owing to the availability of viscosity measurement at this temperature. Using only three important slag properties, $T_{\text {fsol }}, \mu_{1300}$, and an empirical index $n$, this equation reasonably models the entire viscosity curve, and also enables an analytical solution for slag flow in the gap. A typical curve obtained for the casting powder, with composition listed in Table 1, is used in this study, referred to as slag K1 in reference. ${ }^{7)}$ The measured viscosity data and CON1D fitted lines using Eq. (6) are plotted in Fig. 2 using parameters given in Table 2. The measurements show that the slag starts to crystallize at $\sim 1200^{\circ} \mathrm{C}$ ("break" temperature), but does not become fully solid (infinite viscosity) until the final solidification temperature or "softening temperature", which depends on the cooling conditions and ranges from $650^{\circ} \mathrm{C}$ (glassy) to higher temperatures (crystalline conditions). This figure also gives the calculated viscosity curves using equations in previous literature ${ }^{29-31)}$ based on slag composition. Although these equations predict the viscosity at high temperature reasonably, they greatly underpredict the sharp viscosity increase measured at lower temperature. Furthermore, Lee's equation ${ }^{31)}$ predicts a "break" temperature of $983^{\circ} \mathrm{C}$, which is much higher than the measured softening temperature, but lower than the measured break temperature.

The CON1D viscosity model, on the other hand, reasonably matches the measured data. In addition, it enables modeling of the likely viscosity change at low temperature due to slag crystallization, as shown in Fig. 2. To include this effect, a gradual shift in the viscosity curve is proposed 
Table 2. Model input conditions.

\begin{tabular}{|c|c|c|}
\hline Carbon Content, $C \%$ & $0.047(\mathrm{SS} 430)$ & $\%$ \\
\hline Liquidus/Solidus Temperature, $T_{l i q} / T_{\text {sol }}$ & $1502 / 1477$ & ${ }^{\circ} \mathrm{C}$ \\
\hline Steel Density, $\rho_{\text {steel }}$ & 7000 & $\mathrm{~kg} / \mathrm{m}^{3}$ \\
\hline Fraction Solid for Shell Thickness Location, $f_{s}$ & 0.1 & - \\
\hline Mold Thickness at Top (Outer face, including water channel) & 35 & $\mathrm{~mm}$ \\
\hline Mold Dimensions, $Z_{\text {mold_total }} \times{ }_{W_{\text {mold }}}$ & $1200 \times 1560$ & $\mathrm{~mm} \times \mathrm{mm}$ \\
\hline Initial Cooling Water Temperature, $T_{\text {water }}$ & 25 & ${ }^{\circ} \mathrm{C}$ \\
\hline Water Channel Geometry, $d_{c h} \times w_{c h} \times L_{c h}$ & $5 \times 16 \times 21.5$ & $\mathrm{~mm}^{3}$ \\
\hline Cooling Water Velocity, $V_{\text {water }}$ & 11.67 & $\mathrm{~m} / \mathrm{s}$ \\
\hline Mold Conductivity, $k_{\text {mold }}$ & 315 & $\mathrm{~W} / \mathrm{mK}$ \\
\hline Mold Slag Solidification Temperature, $T_{f s o l}$ & $650 \rightarrow 850 *$ & ${ }^{\circ} \mathrm{C}$ \\
\hline Mold Slag Conductivity, $k_{\text {solid }} k_{\text {liquid }}$ & $1.0 \rightarrow 0.5 *$ & $\mathrm{~W} / \mathrm{mK}$ \\
\hline Air Conductivity, $k_{\text {air }}$ & 0.06 & $\mathrm{~W} / \mathrm{mK}$ \\
\hline Slag Layer/Mold Resistance, $r_{\text {contact }}$ & $0.83 \rightarrow 2.5 \times 10^{-4} *$ & $\mathrm{~m}^{2} \mathrm{~K} / \mathrm{W}$ \\
\hline Mold Powder Viscosity at $1300^{\circ} \mathrm{C}, \mu_{1300}$ & 0.421 & Poise \\
\hline Exponent for Temperature Dependence of Viscosity, $n$ & $8.5 \rightarrow 6.0 * *$ & - \\
\hline Slag Density, $\rho_{\text {slag }}$ & 2500 & $\mathrm{~kg} / \mathrm{m}^{3}$ \\
\hline Slag Absorption Coefficient, $a$ & 250 & $1 / \mathrm{m}$ \\
\hline Slag Index of Refraction, $m$ & 1.5 & - \\
\hline Slag Friction Coefficient, $\phi$ & 0.2 & - \\
\hline Mold Powder Consumption Rate, $Q_{\text {slag }}$ & 0.3 & $\mathrm{~kg} / \mathrm{m}^{2}$ \\
\hline Empirical Solid Slag Layer Speed Factor, $f_{v}$ & $0 \rightarrow 0.04 *$ & - \\
\hline Casting Speed, $V_{c}$ & 1.524 & $\mathrm{~m} / \mathrm{min}$ \\
\hline Pour Temperature, $T_{\text {pour }}$ & 1563. & ${ }^{\circ} \mathrm{C}$ \\
\hline Slab Section Size, $W{ }^{\times} N$ & $984 \times 132$ & $\mathrm{~mm} \times \mathrm{mm}$ \\
\hline Nozzle Submergence Depth, $d_{\text {nozzle }}$ & 127 & $\mathrm{~mm}$ \\
\hline Working Mold Length, $Z_{\text {mold }}$ & 1096 & $\mathrm{~mm}$ \\
\hline Oscillation Mark Geometry, $d_{\text {mark }} \times_{w_{\text {mark }}}$ & $0.42 \times 4.0$ & $\mathrm{~mm} \times \mathrm{mm}$ \\
\hline Mold Oscillation Frequency, freq & 150 & $\mathrm{cpm}$ \\
\hline Oscillation Stroke, stroke & 7.5 & $\mathrm{~mm}$ \\
\hline Time Step, $d t$ & 0.005 & $\mathrm{~s}$ \\
\hline Mesh Size, $d x$ & 0.66 & $\mathrm{~mm}$ \\
\hline
\end{tabular}

(a)

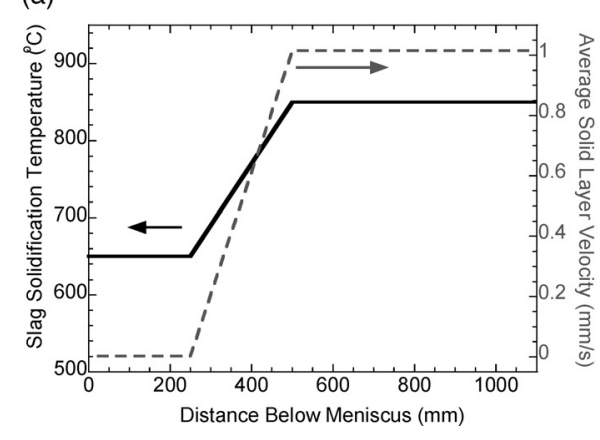

(b)

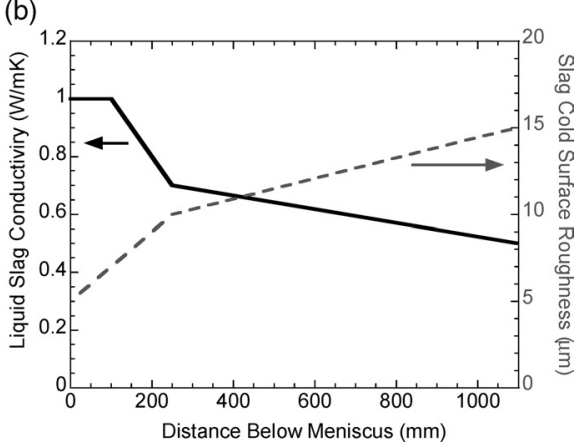

Fig. 3. Input slag properties: (a) slag solidification temperature, $T_{\text {fsol }}$, and average solid layer velocity, $f_{\mathrm{v}}$ and (b) liquid slag conductivity, $k_{\text {liquid }}$, and slag cold surface roughness, for $r_{\text {contact }}$. between $250 \mathrm{~mm}$ to $500 \mathrm{~mm}$ below the meniscus, by adjusting the slag final solidification temperature, $T_{\mathrm{fsol}}$, from $650^{\circ} \mathrm{C}$ to $850^{\circ} \mathrm{C}$ (as shown in Fig. 3(a)) and the index, $n$, from 8.5 to 6.5 . This distance corresponds roughly with the time needed for transformation of each part of the layer, which is discussed later. Over the wide temperature range from $T_{\text {fsol }}$ to $1300^{\circ} \mathrm{C}$, the slag is referred to as "liquid" because it can flow, even though it may be quite viscous, or contain crystals.

\subsubsection{Solid Layer Velocity}

The solid layer velocity is assumed to increase with dis- tance down the mold, as shown in Fig. 3(a). Near the meniscus region, where the solid layer is attached to the mold wall, the solid velocity is set to zero. From $250 \mathrm{~mm}$ below the meniscus, the average solid layer velocity gradually increases, up to $4 \%$ of casting speed at $500 \mathrm{~mm}$ $(1 \mathrm{~mm} / \mathrm{sec})$. This was done to account for the possible fracture or shear-off of the solid layer due to the increasing friction.

\subsubsection{Conductivity}

Due to the wide temperature range $\left(650-1300^{\circ} \mathrm{C}\right)$ across the liquid slag layer, the thermal conductivity is likely to 
vary. Owing to extra difficulty of accurately determining temperature dependent conductivity, and the ease of integrating the equations with a constant value, this model uses an average value, $1.0 \mathrm{~W} / \mathrm{m} \mathrm{K}$ at the meniscus, based on measurements. ${ }^{32)}$ The value was gradually dropped to $0.5 \mathrm{~W} / \mathrm{m} \mathrm{K}$ due to the predicted onset of crystallization of the liquid slag layer, which is expected to be accompanied by gas bubble formation, cracks and other defects that decrease the slag conductivity. The conductivity curve assumed for the simulation is given in Fig. 3(b), which shows the expected drop with distance below the meniscus. The conductivity of the solid slag layer was assumed to remain constant at $0.5 \mathrm{~W} / \mathrm{m} \mathrm{K}^{22}$ )

\subsubsection{Contact Resistance and Glass Transition Tempera- ture}

Below the meniscus, the contact resistance of the interfacial gap generally increases due to the increasing slag surface roughness with decreasing temperature. However, the increased roughness leads to a larger gap resistance, which slightly lowers the heat flux but greatly heats up the solid slag layer. When the slag temperature exceeds its glass transition temperature, $T_{\mathrm{g}}$, assumed to drop from about $500^{\circ} \mathrm{C}$ near the meniscus to about $350^{\circ} \mathrm{C}$ at mold exit, it can flow and consequently smooth the surface of the solid slag layer. This drops the local contact resistance, so the heat flux increases and slag surface temperature decreases again. After a short time, it is assumed that these two effects should equilibrate. Thus, the thermal contact resistance was adjusted in this study until the slag cold face temperature just barely matches the slag softening temperature. The resulting roughness profile, expressed as an equivalent air gap, increases from $5 \mu \mathrm{m}$ at the meniscus to $15 \mu \mathrm{m}$ at the mold exit. Dividing the roughness by the air conductivity, this corresponds to a contact resistance of $0.83 \times 10^{-4}$ at the meniscus and then decreases to $2.5 \times 10^{-4} \mathrm{~m}^{2} \mathrm{~K} / \mathrm{W}$ at the mold exit, which is consistent with Yamauchi's measurements. ${ }^{33)}$

Other input conditions are listed in Table 2. All input parameters governing the interfacial gap properties are chosen to be consistent with the conditions actually experienced in the gap according to measurements in this or previous work. ${ }^{22,34)}$

\subsection{Interfacial Friction Model}

The time-dependent friction shear stress along the mold wall, $\tau_{x z}(x=0)$, and the axial stress generated in the solid slag layer, $\sigma_{z}$, are found during the sinusoidal mold-oscillation cycle by solving the following force equilibrium equation:

$$
\frac{\partial \tau_{x z}}{\partial x}+\frac{\partial \sigma_{z}}{\partial z}=0
$$

(a)

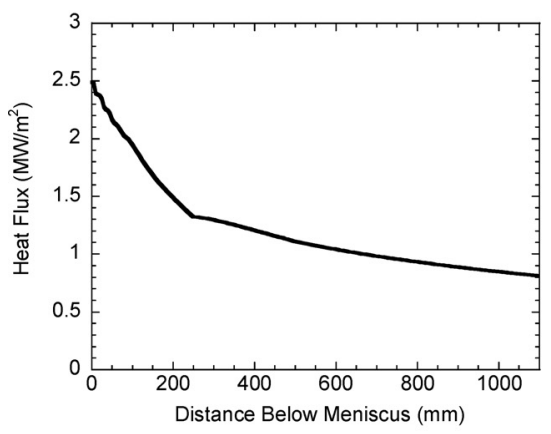

(b)

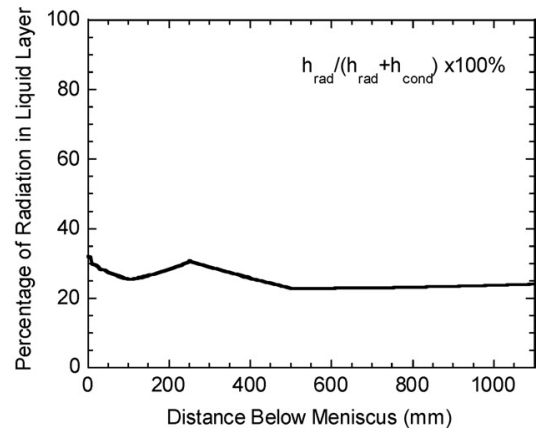

This equation is subject to the shear stress imparted by the liquid slag layer, $\tau_{\mathrm{s} / 1}$ from the solution to Eq. (5), and the shear stress transmitted to the mold by Coulomb friction with the solid slag layer due to relative motion of the mold and shell. The maximum mold shear stress is:

$$
\tau_{\max }=\phi \sigma_{x}
$$

where the normal stress, $\sigma_{x}$, must balance the ferrostatic pressure from the liquid steel on the wideface shell. The shear stress transmitted to the mold wall is the minimum of the maximum friction stress and the solid/liquid interface stress:

$$
\tau_{\text {mold }}=\min \left(\frac{v}{1-v} \rho_{\text {steel }} g d_{\text {solid }}+\tau_{\mathrm{s} / 1}, \tau_{\max }\right) \ldots \ldots
$$

The total mold friction force on each wideface, $F(\mathrm{kN})$, is found by integrating the mold shear stress over the length of the mold:

$$
F=\int_{0}^{Z_{\text {mold-total }}} \tau_{\text {mold }} W_{\text {mold }} d z
$$

Solid slag tends to remain attached to the mold wall, especially near the meniscus. When friction on the mold side cannot compensate the shear stress on the slag solid/liquid interface, axial stress builds up in the solid slag layer. If the powder consumption rate drops below a critical level, the axial tensile stress can exceed the slag fracture strength during the upstroke, so the solid slag breaks and eventually moves down the mold wall. Further details on this model and its validation can be found elsewhere. ${ }^{3,27)}$

\section{Simulation Results}

\subsection{Heat Transfer}

Figures 4 to 6 show heat transfer predictions for this case as a function of distance down the mold. With the measured total consumption rate of $0.3 \mathrm{~kg} / \mathrm{m}^{2}$ (consumption not including slag carried in oscillation marks, $Q_{\text {lub }}=$ $0.09 \mathrm{~kg} / \mathrm{m}^{2}$ ), the mean heat flux in the mold is $1.21 \mathrm{MW} / \mathrm{m}^{2}$, which gives a $5.6^{\circ} \mathrm{C}$ increase in cooling water temperature. This matches with the measured $6.1^{\circ} \mathrm{C}$ increase, within a reasonable measurement error range.

\subsubsection{Heat Flux}

Figure 4(a) shows the heat flux profile predicted down the mold. Its shape that drops sharply from a peak at the meniscus followed by gradual decrease is typical of previous work. The radiation is $22-32 \%$ of the total heat flux, as shown in Fig. 4(b). This should drop after partial crystallization, owing to a likely increase in absorption coefficient, $a$, which was not included in the current model. Repeating
Fig. 4. Predicted mold heat transfer: (a) heat flux into the mold and (b)fraction of heat transfer by radiation. 
(a)

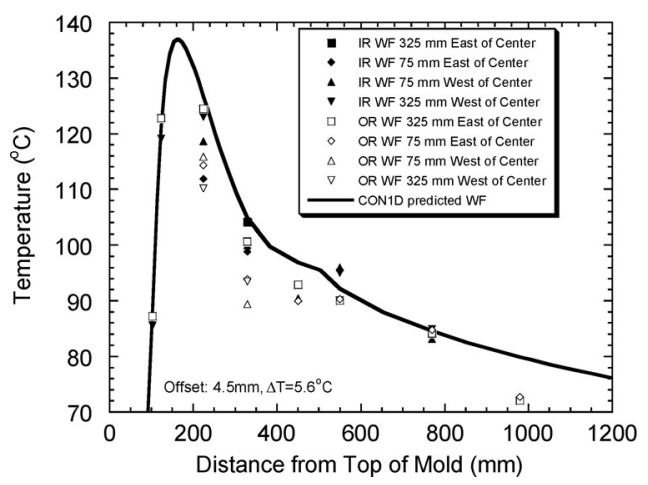

(b)

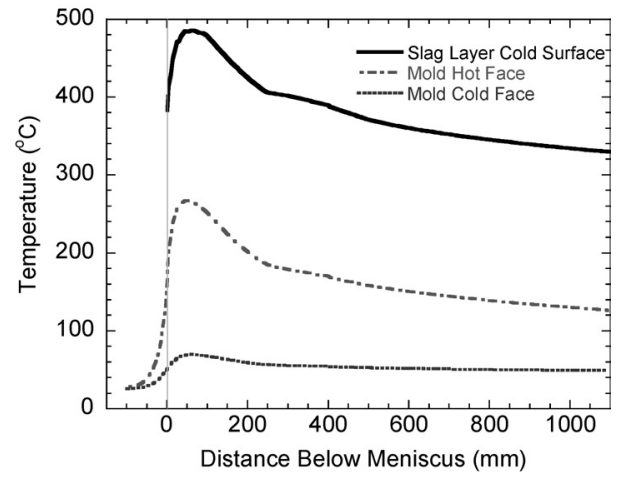

Fig. 5. Mold wideface temperature predictions compared with measurements: (a) temperature at thermocouple location (symbols are measurements) and (b) mold and slag layer temperature predictions.

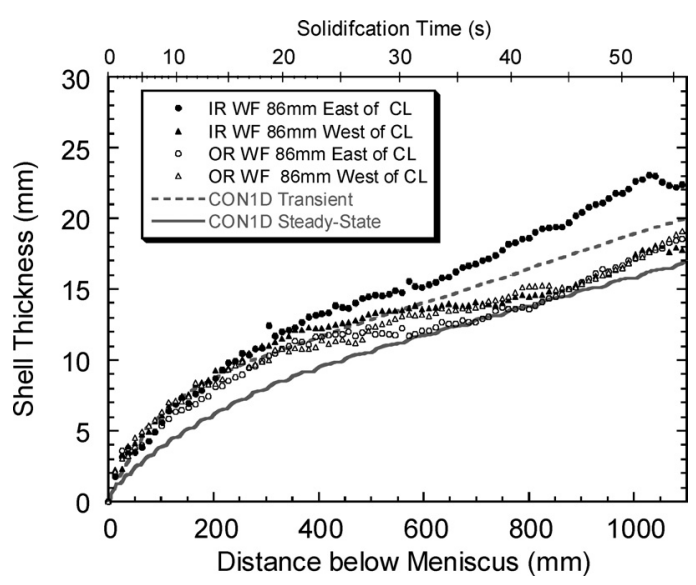

Fig. 6. Solidified shell thickness, comparing predictions (lines) and breakout shell measurements (symbols).

the simulation and neglecting radiation completely, the total heat flux to the mold drops by an average of only $13 \%$ (ranging from a $36 \%$ drop at the meniscus to a $4 \%$ drop at mold bottom). This shows that the conduction resistances of the slag layer and steel shell control heat transfer, and grow in importance with distance below the meniscus.

\subsubsection{Mold Temperature}

Because the mold geometry near the embedded thermocouples is complicated, ${ }^{35)} 3-\mathrm{D}$ heat computations were performed by Langeneckert et al. on regions of this copper mold near the thermocouples, ${ }^{34)}$ including heat losses along the thermocouple wire itself. From these results, an offset in thermocouple position of $4.5 \mathrm{~mm}$ toward the mold hot face was found to adjust the CON1D prediction to match the 3-D model predictions for this mold. ${ }^{34,36)}$ Figure 5(a) compares the measured thermocouple temperature and predictions (using this offset) for the central region of the mold wide face. The agreement indicates the consistency between the mold thermocouple measurements and the cooling water temperature measurement.

In addition to the mold hot face and cold face temperature, Fig. 5(b) includes the temperature profile of the solid slag layer cold surface. The temperature drop from the slag layer surface to the mold hot face corresponds to the contact resistance between the mold and the slag layer. The contact resistance is low at the meniscus because the high temperature softens the solid slag layer and allows its surface to become smooth. Down the mold, the slag surface temperature decreases, so the slag layer cannot deform as easily and retains a rougher surface. This increases the contact resistance between the sold slag layer and the mold.

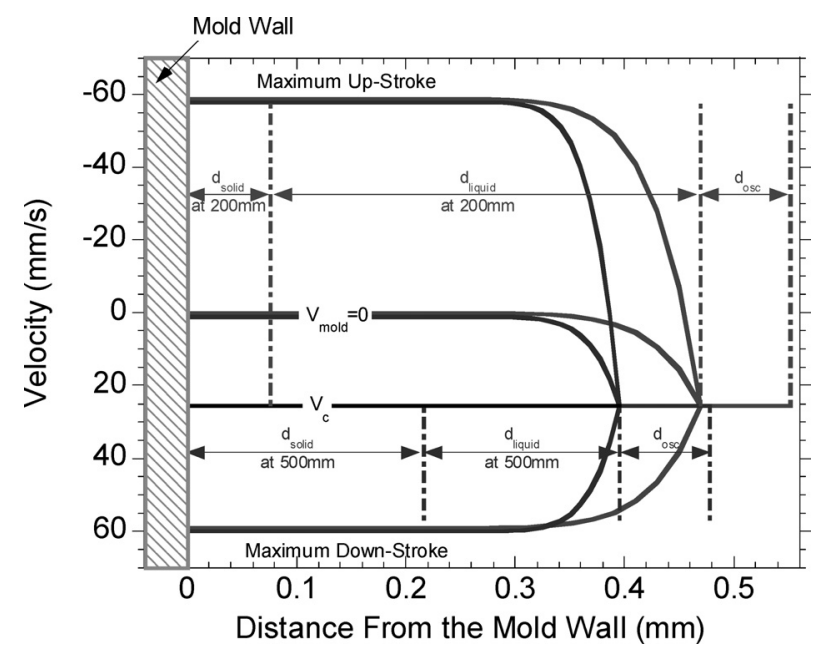

Fig. 7. Slag layer velocity distribution predicted at $200 \mathrm{~mm}$ and $500 \mathrm{~mm}$ below meniscus.

\subsubsection{Steel Shell Thickness}

The predicted shell thickness profiles are compared in Fig. 6 with measurements down a breakout shell that occurred under similar casting conditions. The transient profile was calculated with a correction to account for the extra solidification time that occurred while liquid metal was draining during the breakout. ${ }^{3,37)}$ Reasonable agreement is obtained, assuming a solid fraction of 0.1 . Figure 6 also contains the shell thickness predicted for steady state conditions that corresponds to the other results in this paper.

\subsubsection{Slag Layer}

Figure 7 gives the velocity distribution in the slag layers computed across the gap thickness at two locations, $200 \mathrm{~mm}$ and $500 \mathrm{~mm}$ below the meniscus, in the laboratory frame of reference. The profile varies during the oscillation cycle. The thickness and viscosity differences arising from the different temperature profiles cause obvious differences near the shell surface. There is little effect on solid slag velocity, which follows the mold movement. Figure 8 shows the typical temperature profile at $500 \mathrm{~mm}$ below the meniscus. The generally steep temperature change across the interface makes the temperature gradients in the mold and steel shell look almost flat in comparison. The most sudden change in temperature occurs at the solid slag/mold surface, which depends on the slag roughness and the low conductivity of the vapor filling in the intermittent spaces. Note that the volume-averaged oscillation mark depth, $d_{\mathrm{osc}}$, is used to satisfy the mass balance of slag consumption (Fig. 7); while the heat-balance based oscillation mark depth, $d_{\text {eff }}$, is used to calculate temperature profile across the gap 
(Fig. 8).

Figure 9 compares the magnitudes of thermal resistances predicted for different heat transfer mechanisms across the gap as they vary with distance down the mold. The liquid slag layer is the most significant barrier to heat transfer near the meniscus, and its resistance changes little down the mold. The solid slag layer increases in thickness and importance with distance down the mold, which is similar to the behavior of the solid steel shell, as discussed earlier. The high value of the radiation resistance accounts for the 2-3 times greater importance of the parallel heat transfer path of conduction through the liquid and glassy slag layers, as also shown in Fig. 4. The contact resistance is smallest, so like the copper mold itself, has little effect on the overall heat transfer rate. However, it has a critical influence on the solid slag temperature, and its corresponding behavior.

The variation in slag layer thicknesses predicted down the mold is presented in Fig. 10. The shift of the viscosity curve, together with the slow movement of the solid slag layer, accounts for some of the slag consumption and also increases the average liquid layer velocity with distance

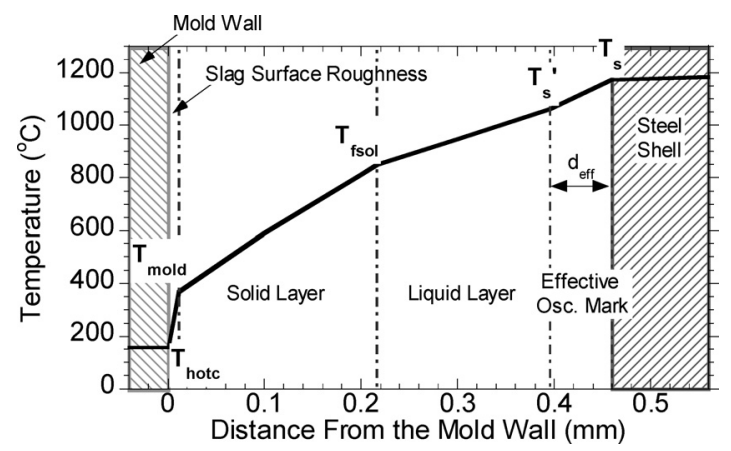

Fig. 8. Temperature profile predicted at $500 \mathrm{~mm}$ below meniscus.

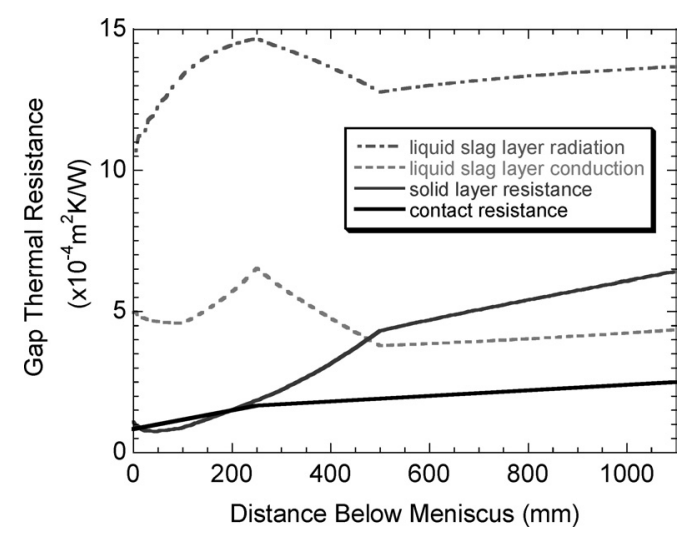

Fig. 9. Variation down the mold of thermal resistances across the interfacial shell-mold gap. down the mold. The liquid layer includes both liquid slag and partially-crystallized slag above the final solidification (softening) temperature. Its thickness decreases down the mold as the shell temperature drops, but maintains a continuous lubricating layer for these conditions. For the steadystate conditions simulated here, the solid slag layer thickness increases with distance down the mold, according to the lower heat flux, and corresponding lower temperature, especially with the increased softening temperature. Together, the total slag layer thickness has relatively little change over the whole mold length, which agrees with the observations of slag samples taken from the real operating caster. $^{38)}$

The slag layer varies in thickness locally according to the depth of the oscillation marks. The average equivalent thickness of the oscillation marks, $d_{\text {eff }}$, and volume-averaged oscillation mark depth are also included in Fig. 10. The volume transported by the oscillation marks thicknesses accounts for $0.207 \mathrm{~kg} / \mathrm{m}^{2}$ or $68.9 \%$ of the total mold powder consumption.

It is noted that the slag layer softening interaction with surface roughness may set up a stabilizing effect on heat transfer in the mold. A rougher slag surface tends to create a larger interfacial resistance, lower heat transfer, and consequently hotter slag layer. This in turn causes the solid layer to become smoother, which lowers the gap resistance, and increases heat transfer. These opposing effects should tend to stabilize both the roughness and heat transfer. This means that minor changes in surface roughness tend to be compensated by slag softening due to the corresponding changes in cold surface temperature of the slag layer, and thereby tend to maintain uniform heat transfer.

\subsection{Crystallization Behavior}

Figure 11 shows the cooling history of different layers in the interfacial gap. The measured Continuous-Cooling-

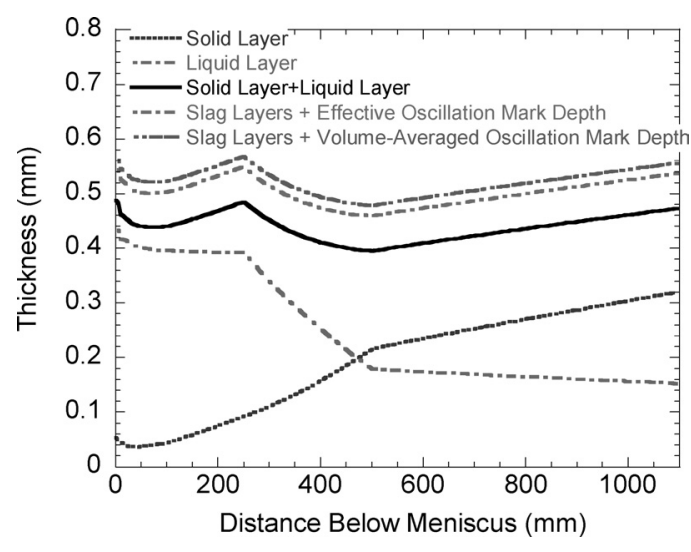

Fig. 10. Slag layer thicknesses predicted down the mold. (a)

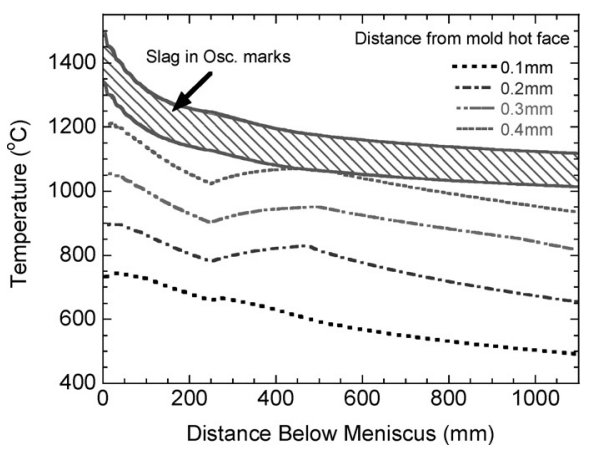

(b)

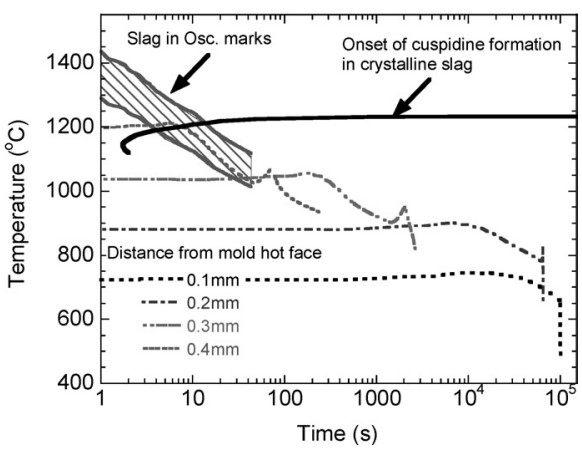

Fig. 11. Predicted slag layer cooling histories: (a) slag temperature down the mold, showing variation across the gap and (b) temperature history at different gap positions with superimposed measured CCT curve. ${ }^{7}$ 
(a)

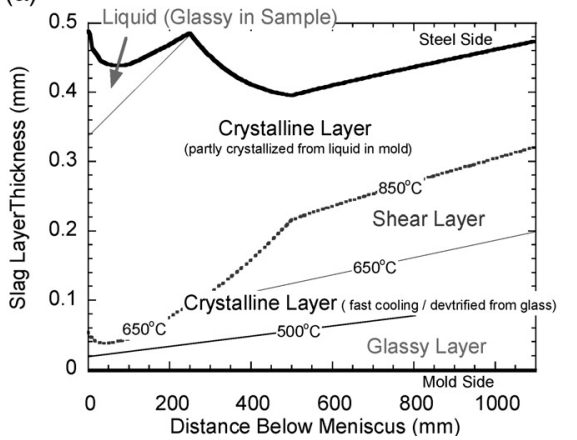

(b)

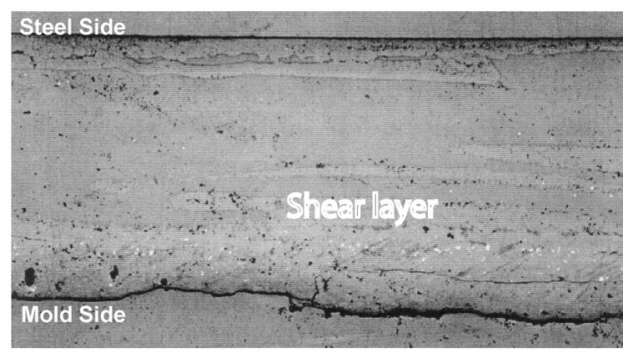

Fig. 12. Comparison of proposed slag layer microstructure in the interfacial gap and slag sample collected during cap-off: (a) schematic of slag layer and (b) slag sample. ${ }^{2)}$

Transformation (CCT) curve ${ }^{7)}$ for crystalline slag is superimposed on Fig. 11(b) to estimate the onset of crystallization of this slag. The slag layer in the oscillation marks begins to cross the CCT curve at $\sim 100 \mathrm{~mm}$ below the meniscus $(\sim 4 \mathrm{~s})$. This indicates the onset of crystallization, which was expected to cause a decrease in slag conductivity, which was incorporated into the input data (Fig. 3(b)). Therefore, heat flux is impeded and the temperature in the slag layers decreases down the mold. This temperature decrease in turn sustains an increase in roughness of the solid slag layer cold surfaces. A glassy layer is predicted to form initially against the mold wall by quenching below the nose of the CCT curve. These locations near the mold wall crystallize after longer times, but at a similar distance down the mold, owing to the slower average downward movement of those colder layers.

As the fraction of crystals in the liquid layer increases, the viscosity of the slag also increases. Thus, the final solidification temperature, $T_{\mathrm{fsol}}$, and viscosity index, $n$, were adjusted with distance down the mold according to Figs. 2 and 3. The thinner liquid layer (see Fig. 10) causes shear stress and axial tensile stress to build up in the liquid layer. If shear stress in the slag layer reaches its shear strength before the axial stress accumulates to its fracture strength, the slag layer could internally fail by longitudinal shear. This would release the axial stress and avoid the more serious problem of slag fracture and shear off from the mold wall that is sometimes observed. ${ }^{2)}$ Furthermore, the increased slag crystallinity might help the solid slag layer to better attach to the mold wall, ${ }^{39)}$ increasing the friction coefficient at the slag/mold interface. ${ }^{27}$ ) This would lower the axial stress build-up in the slag layer, lessen the likelihood of axial fracture and promote inter-layer shearing.

In the simulation, failure by either fracture or shearing was roughly approximated by giving the solid layer the average velocity profile shown in Fig. 3(a). This solid layer movement accelerates the slag consumption, so the liquid layer thickness decreases quickly. Correspondingly, the heat flux is enhanced and the slag layer temperature rebounds. This causes a slight temperature hump in the middle of the mold, which is confirmed by the time-averaged thermocouple measurements in the real steel caster. ${ }^{2,40}$ Lower in the mold, when the entire slag layer has crystallized, the heat transfer is relatively stable at a slightly lower value, due to the slightly thicker slag layer.

The results in Fig. 8 also suggest that some time is required to achieve this steady-state scenario. The layer adjacent to the mold wall take time on the order of several hours to crystallize. Prior to that time, the higher-conductivity glassy layer on the mold wall is predicted to be thicker, producing higher heat flux and better lubrication. As crystallization of the slag against the mold wall progresses at longer times, axial fracture becomes more likely. This upsets the steady scenario proposed, as the slag is carried out quickly as a sheet, which indeed has been observed previously. ${ }^{40)}$ The start of casting is expected to differ also, because part of the slag consumption is required to build up the steady slag layers. These transient processes should occur periodically on the time scale of hours.

Figure 12(a) proposes a schematic of the typical microstructure distribution expected in the interfacial gap, based on the simulation results for this caster under these characteristic steady-state conditions. According to the results, crystalline layers dominate the slag film. Sheared layers are mostly likely found near the middle of the film, at the interface between the liquid and solid layers at the locations down the mold where the shear stress exceeds the slag strength. Figure 12(b) shows a micrograph of a cross section through a piece of slag film taken from the mold wall at the end of casting (cap-off) at about $300 \mathrm{~mm}$ from the top of the mold, that has only slightly different composition than slag $\mathrm{K} 1$ and is about $0.9 \mathrm{~mm}$ thick. ${ }^{2,40)}$ This is consistent with the thickness predicted by the model, which varied from a minimum of $\sim 0.5 \mathrm{~mm}$ (see Fig. 10) to a maximum of $0.9 \mathrm{~mm}$ in oscillation marks. It appears to show sheared layers in the film, ${ }^{2)}$ at the same general location as predicted in Fig. 12(a). The model predicts a short length of liquid layer on the steel side near the meniscus, which should be observed as glass if the air-quenched cap-off sample could be obtained. On the mold side, a thin $(\sim 0.05 \mathrm{~mm})$ glassy layer is also predicted. This is not seen in the cap-off film, which was obtained for slightly different conditions. This is likely due to the devitrification of the glassy layer, which would happen if the contact resistance were able to increase the slag surface temperature to above a critical temperature. The CCT results of this work suggest that the critical temperature for devitrification is around $500-600^{\circ} \mathrm{C}$, which is consistent with previous measurements of $650^{\circ} \mathrm{C}$ for industrial slags ${ }^{7,10,41)}$ and a few hundred Celsius degrees higher for synthetic slags. ${ }^{10,41)}$

Slag film samples were taken from an experimental apparatus, which was constructed to simulate the gap in the real caster. ${ }^{22)}$ The slag composition, B2 given in Table 1 in Ref. 22 ), is the same as that of slag $\mathrm{K} 1$. The samples were observed under SEM and Fig. 13 shows the backscatter electron (BSE) images. This figure reveals a complex multiplelayered structure that is similar in appearance to the slag sample removed from the operating continuous casting mold. The layers appear mainly crystalline, and correspond to different cooling rates. On the mold side, the fine and close dendrite structure is consistent with the fast cooling experienced there. In the middle of the film, the grains are uniform with a larger size. The steel side shows unevensized grains, which indicates that there was a significant growth of a few grains, formed during slow cooling, within a glassy background that was likely formed during fast air 


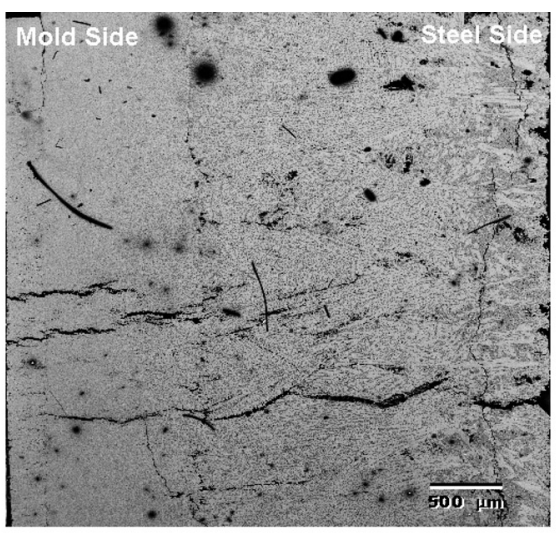

(a) Entire sample thickness

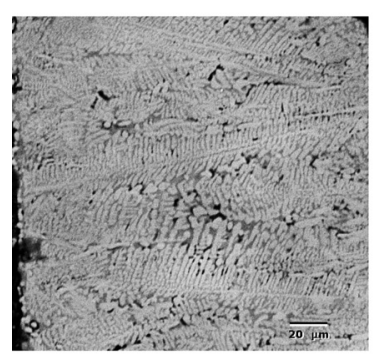

(b) Mold Side

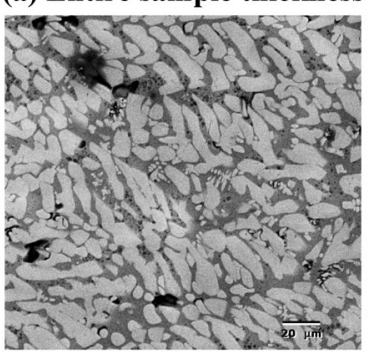

(c) Middle Layer

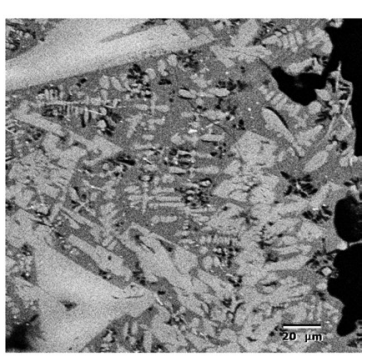

(d) Steel Side

Fig. 13. BSE images of slag sample from experimental apparatus, with close-ups at different distances across the gap.

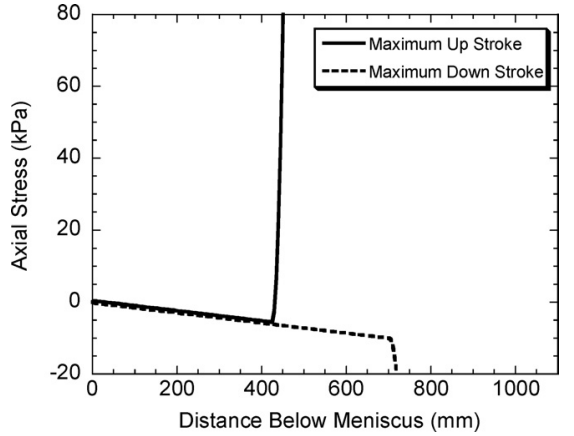

Fig. 14. Solid slag layer axial stress distribution down the mold. (a)

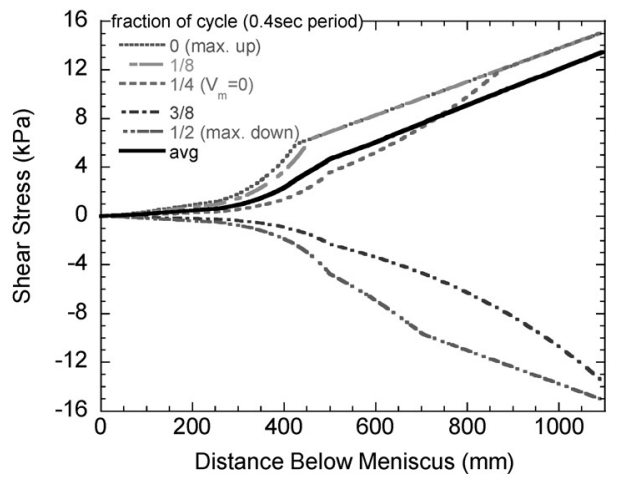

cooling after the sample was removed.

\subsection{Friction}

In previous work, ${ }^{7)}$ friction measurements determined a relatively stable sliding friction coefficient for solidified mold slag/metal interfaces of 0.2 , which was taken as the static friction coefficient in this work. Figure 14 shows that the axial stress builds up quickly in the solid slag layer at about $400 \mathrm{~mm}$ below the meniscus. This indicates the possible position of slag shear or fracture.

Figure 15 shows the shear stress down the mold predicted from the CON1D model at different times during the oscillation cycle. The shear stress increases with distance down the mold. The liquid-layer-controlled friction (nearly sinusoidal shape over the oscillation cycle) changes to solid-layer-controlled friction (more square-shaped) at around $400 \mathrm{~mm}$ below the meniscus, where the slag layer shear is predicted to occur.

Integrating each shear stress line gives the total friction force over the mold face during the half oscillation cycle, which is shown in Fig. 16(a). This stress acting on the slag layer shifts from tension to compression when the oscilla-
Fig. 15. Shear stress at solid/liquid slag layer interface: (a) shear stress down the mold at different times during oscillation cycle and (b) local shear stress evolution over half oscillation cycle.

tion cycle shifts from positive strip to negative strip. Its amplitude is roughly consistent with the typical mold friction stresses measured in actual steel continuous casting molds. ${ }^{27)}$ The corresponding total mold force varies from $7.6 \mathrm{kN}$ to $-6.7 \mathrm{kN}$ over the cycle as shown in Fig. 16(b), which is obtained by multiplying the results Fig. 16(a) by the mold area. Further plant measurements of in-mold friction are needed together with the interpretations provided by the model presented here, in order to better understand interfacial phenomena and to improve the casting process.

\section{Conclusions}

A computational model, CON1D, is applied to interpret a metallographic examination of slag samples to understand interfacial mold slag behavior in a typical commercial slab caster. The model simulates heat transfer, lubrication, fluid flow, and stress in the slag layers, in addition to heat transfer in the mold and the solidifying steel shell. The effects of a shift in the viscosity curve, and a decrease in the liquid slag conductivity due to partial crystallization, are incorporated based on the continuous-cooling time-temperature 
(a)

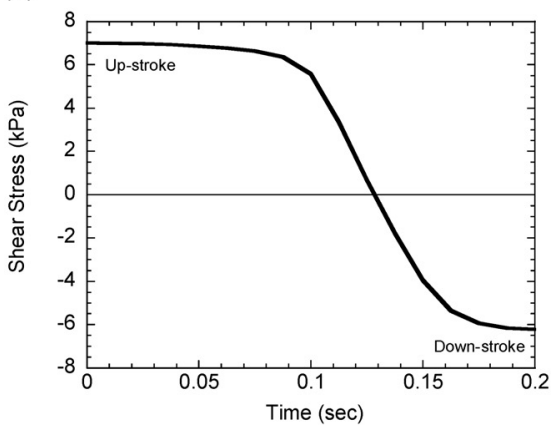

(b)

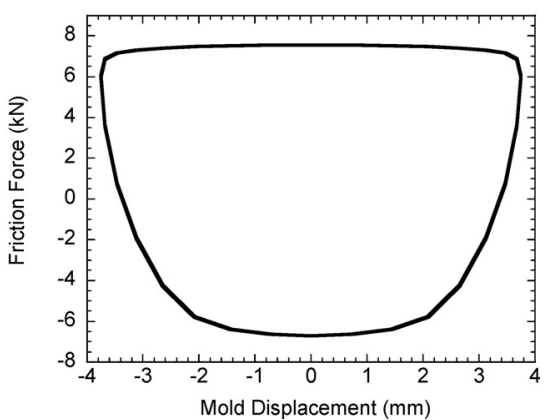

Fig. 16. Mold friction variation during oscillation cycle: (a) average mold shear stress vs. time and (b) total friction force $v s$. mold displacement. transformation diagram for the slag. The contact resistance at the mold/slag interface is found by assuming the slag layer flows until its cold surface temperature approaches the glass transition temperature of the slag. The resulting roughness profile of the solid slag layer increases with distance below the meniscus according to a predicted decrease in slag cold surface temperature down the mold.

A mechanism is developed for the formation of the shape and microstructure of the glassy and crystalline slag layers. When the shear stress exceeds the slag shear strength before the axial stress accumulates to the fracture strength, the slag could fail, most likely by shear longitudinally inside the layers. The model also predicts the corresponding heat transfer and friction between the steel shell, the interface, and the copper mold. The model predictions of heat transfer and shell thickness match plant measurements. The predicted shape and microstructure of the slag layers compare favorably with the samples. The model reveals new insights into the understanding and control of interfacial slag layers in the continuous casting process.

\section{Acknowledgements}

The authors would like to thank the University of Illinois at Urbana-Champaign for financial support from the Continuous Casting Consortium and for microscopy support from the Center for Microanalysis of Materials, which is partially supported by the U.S. Department of Energy under grant DEFG02-91-ER45439. Special thanks go to Dr. Ronald O'Malley and AK Steel for collecting the operating data and experimental measurements and helpful advice.

\section{REFERENCES}

1) C. A. Pinheiro, I. V. Samarasekera and J. K. Brimacombe: Iron Steelmaker, 22 (1995), No. 2, 37.

2) R. J. O'Malley: 82nd Steelmaking Conf., Iron and Steel Society/ AIME, Warrendale, PA, 82 (1999), 13.

3) Y. Meng and B. G. Thomas: Metall. \& Mater. Trans. B, 34B (2003), No. 5,685 .

4) M. S. Jenkins, B. G. Thomas, W. C. Chen and R. B. Mahapatra: 77th Steelmaking Conf. Proc., ISS, Warrendale, PA, (1994), 337.

5) H.-J. Shin, G. G. Lee, W.Y. Choi, S. M. Kang, J. H. Park, S. H. Kim and B. G. Thomas: Iron \& Steel Technology, 2 (2005), No. 9, 56.

6) K. C. Mills: Ironmaking Steelmaking, 15 (1988), No. 4, 175.

7) Y. Meng, B. G. Thomas, A. A. Polycarpou, A. Prasad and H. Henein: Canadian Metallurgical Quarterly, 45 (2006), No. 1, 79.

8) M. M. Wolf: Continuous Casting 1997, Vol. 9: Initial Solidification and Strand Surface Quality of Peritectic Steels, ISS/AIME, Warrendale, PA, (1997), 211.

9) M. S. Bhamra, M. G. Charlesworth, S. Wong, D. Sawyers-Villers and A. W. Cramb: 54th Electric Furnace Conf., ISS/AIME, Warrendale, PA, (1996), 551.

10) C. Orrling, A. W. Cramb, A. Tilliander and Y. Kashiwaya: Iron Steelmaker, 27 (2000), No. 1, 53.

11) Y. Umezawa, T. Matsushita and S. Seetharaman: 3rd Int., Cong. on Science \& Technology of Steelmaking, AIST, Warrendale, PA, (2005), 781.

12) J. Cho, H. Shibata, T. Emi and M. Suzuki: ISIJ Int., 38 (1998), No. 5,

\section{0.}

13) M. R. Ridolfi, B. G. Thomas, G. Li and U. D. Foglia: Rev. Metall., Cah. Inf. Tech., 91 (1994), No. 4, 609.

14) M. S. Jenkins and B. G. Thomas: 80th Steelmaking Conf. Proc. 1997, ISS/AIME, Warrendale, PA, (1997), 285.

15) T. Cimarelli: Metall. Ital., 89 (1997), No. 9, 31

16) G. J. W. Kor: Continuous Casting of Steel, 2nd Process Technology Conf., ISS/AIME, Warrendale, PA, USA, (1981), 124.

17) I. B. Risteski: Rev. Metal., 28 (1992), No. 5, 288.

18) S. Ogibayashi: 85th Steelmaking Conf., ISS/AIME, Warrendale, PA, (2002), 175.

19) J. A. DiLellio and G. W. Young: Metall. Mater. Trans. B, 26B (1995), No. 6,1225 .

20) B. G. Thomas, B. Ho and G. Li: Alex McLean Symp.: Process Fundamentals, Liquid Metal Processing for Cleanliness, Novel and Conventional Casting, and Novel Process Technologies, Alex McLean Symposium Proc., Iron and Steel Society, Warrendale, PA, (1998), 177.

21) Y. Meng: PhD Thesis, University of Illinois, (2004).

22) D. T. Stone and B. G. Thomas: Can. Metall. Q., 38 (1999), No. 5, 363.

23) J. Sengupta, H.-J. Shin, B. G. Thomas and S.-H. Kim: Acta Mater, 54 (2005), No. 4, 1165.

24) B. G. Thomas, D. Lui and B. Ho: Sensors and Modeling in Materials Processing: Techniques and Applications, Minerals, Metals and Materials Society/AIME, Warrendale, PA, (1997), 117.

25) M. R. Ozgu and B. Kocatulum: 76th Steelmaking Conf., Proc. ISS, Warrendale, PA, (1993), 301.

26) G. A. Geist: 83rd Steelmaking Conf., Proc. ISS/AIME, Warrendale, PA, (2000), 389.

27) Y. Meng and B. G. Thomas: Metall. Mater. Trans. B, 34B (2003), No. 5, 707 .

28) B. Ho: MS Thesis, University of Illinois at Urbana-Champaign, (1992).

29) P. V. Riboud, Y. Roux, L. D. Lucas and H. Gaye: Fachber. Huttenprax. Metallweiterverarb., 19 (1981), No. 8, 859.

30) K. Koyama, Y. Nagano, K. Nagano and T. Nakano: Nippon Steel Tech. Rep., 34 (1987), 41.

31) I. R. Lee, J. W. Kim, J. Choi, O. D. Kwon and Y. K. Shin: Proc. Conf. on Continuous Casting of Steel in Developing Countries, Chinese Society of Metals, Beijing, China, (1993), 814.

32) K. Nagata and K. S. Goto: Proc. of 2nd Int. Symp. on Metallurgical Slags and Fluxes, ed. by H. A. Fine and D. R. Gaskell, TMS AIME, Warrendale, PA, (1984), 875.

33) A. Yamauchi, K. Sorimachi, T. Sakuraya and T. Fujii: ISIJ Int., 33 (1993), No. 1, 140.

34) M. M. Langeneckert: Master Thesis, University of Illinois, (2001).

35 ) B. G. Thomas, R. J. O'Malley and D. Stone: Modeling of Casting, Welding, and Advanced Solidification Processes VIII, TMS, Warrendale, PA, (1998), 1185.

36) B. G. Thomas, R. J. O'malley, T. Shi, Y. Meng, D. Creech and D. Stone: Modeling of Casting, Welding and Advanced Solidification Process IX, ed. by P. R. Sahm, P. N. Hansem and J. G. Conley, TMS, Warrendale, PA, (2000), 769.

37) D. Stone: M.S. Thesis, University of Illinois at Urbana-Champaign, (2000).

38) R. J. O'Malley: Private communication, (1999).

39) M. S. Jenkins: Ph D Thesis, Monash University, Australia, (1998).

40) R. J. O'Malley and J. Neal: Proc. METEC Cong. 99, Verein Deutscher Eisenhüttenleute, Düsseldorf, (1999), 195.

41) Y. Kashiwaya, C. E. Cicutti and A. W. Cramb: ISIJ Int., 38 (1998), No. 4, 357. 